\title{
The novel gene $C p E d i-9$ from the resurrection plant $C$. plantagineum encodes a hydrophilic protein and is expressed in mature seeds as well as in response to dehydration in leaf phloem tissues
}

Received: 9 December 2003 / Accepted: 28 February 2004 / Published online: 10 June 2004

(C) Springer-Verlag 2004

\begin{abstract}
The resurrection plant Craterostigma plantagineum Hochst. is used as an experimental system to investigate desiccation tolerance in higher plants. A search for genes activated during early stages of dehydration identified the gene $C p E d i-9$, which is expressed in mature seeds and in response to dehydration in the phloem cells of vascular tissues of leaves. Elements for the tissue-specific expression pattern reside in the isolated promoter of the $C p E d i-9$ gene, as shown through the analysis of transgenic plants. The $C p E d i-9$ promoter could be a suitable tool for expressing genes in the vascular system of dehydrated plants. $C p E d i-9$ encodes a small $(10 \mathrm{kDa})$ hydrophilic protein, which does not have significant sequence homologies to known genes. The predicted protein CpEDI-9 shares some physicochemical features with LEA proteins from plants and a nematode. Based on the unique expression pattern and on the nucleotide sequence we propose that $C p E d i-9$ defines a
\end{abstract}

This article is dedicated to Prof. Dr. Francesco Salamini on the occasion of his 65th birthday and his departure from the Max Planck Institute in Köln

M. J. Rodrigo · C. Bockel · A.-S. Blervacq · D. Bartels $(\bowtie)$

Max Planck Institut für Züchtungsforschung,

Carl von Linné Weg 10, 50829 Köln, Germany

E-mail: dbartels@uni-bonn.de

Tel.: + 49-228-732070

Fax: + 49-228-731697

Present address: M. J. Rodrigo

Departamento de Ciencia de Alimentos,

Instituto de Agroquímica y Tecnología de Alimentos

(IATA-CSIC), Apartado correos 73, Burjassot,

46100 Valencia, Spain

Present address: A.-S. Blervacq

Physiologie de la différenciation végétale,

UPRES3569-IFR118-ERT 1016, Université des Sciences

et Technologies de Lille, Bâtiment SN2-3ème étage,

59650 Villeneuve dASCQ Cedex, France

Present address: D. Bartels

Institut für Molekulare Physiologie und Biotechnologie der Pflanzen, Rheinische Friedrich-Wilhelms-Universität Bonn, Kirschallee 1, 53115 Bonn, Germany new class of hydrophilic proteins that are supposed to contribute to cellular protection during dehydration. This group of proteins may have evolved because desiccation tolerance requires the abundant expression of protective proteins during early stages of dehydration in all tissues.

Keywords Craterostigma - Early dehydration-induced protein $\cdot$ Hydrophilic protein $\cdot$ Phloem promoter analysis $\cdot$ Resurrection plant

Abbreviations ABA: Abscisic acid - ABRE:

ABA-responsive element - Edi: Early dehydration induced - GUS: Glucuronidase - LEA: Late embryogenesis abundant $\cdot$ MU: Methylumbelliferone

\section{Introduction}

Dehydration is a common environmental stress to which plants are exposed. Tolerance to dehydration rarely occurs in vegetative plant tissues while angiosperm seeds and pollen are able to survive extreme dehydration conditions (Leopold 1992; Bartels et al. 1996; Phillips et al. 2002). A unique exception among higher plants is the small group of resurrection plants, which have developed the ability to recover from severe water loss in vegetative tissues (Gaff 1971). A representative of the resurrection plants is Craterostigma plantagineum, a member of the Scrophulariaceae, which can lose most of its cellular water and recover from such severe dehydration within $24 \mathrm{~h}$ of contact with water (Bartels et al. 1990). Hence $C$. plantagineum provides an excellent system to study the molecular basis of desiccation tolerance in higher plants. During dehydration, many new transcripts rapidly accumulate in vegetative tissues of $C$. plantagineum and it has been supposed that the corresponding gene products contribute to the protection of cellular structures and metabolites during severe water stress (Bockel et al. 1998; Bartels and Salamini 2001). 
It has previously been shown that a diverse group of hydrophilic proteins, called LEA ( = Late Embryogenesis Abundant) proteins are one of the most abundant groups of proteins that accumulate in the vegetative tissues of C. plantagineum in response to water stress (Piatkowski et al. 1990; Schneider et al. 1993; Velasco et al. 1998; Ditzer et al. 2001). LEA proteins were first characterised in cotton embryos where they accumulate to high levels during the last stage of seed formation (Galau et al. 1986). Besides dehydration, the expression of LEA proteins can be induced in vegetative tissues in response to freezing or salt stress, or by treatment with the phytohormone abscisic acid (ABA; Piatkowski et al. 1990; Schneider et al. 1993). The endogenous ABA concentration increases in vegetative tissues upon dehydration and at late stages of seed formation. It is known to play an important role in several aspects of seed development, and it is crucial for the plant responses to environmental stress (Leung and Giraudat 1998). LEA proteins have been classified into six groups on the basis of sequence similarities (Ingram and Bartels 1996; Colmenero-Flores et al. 1997; Cuming 1999). Often no significant homology on the sequence level has been detected between LEA proteins of different families, although most of them share common features such as high hydrophilicity, biased amino acid composition, stability after boiling and the prediction to exist as random coil structures. Some conserved motifs within LEA proteins are predicted to form amphipathic $\alpha$-helices, which may be important for their function (Dure 1993; Ingram and Bartels 1996; Close 1997). Recent findings suggest that $\alpha$-helices preferentially occur under dehydration conditions (Goyal et al. 2003). The accumulation pattern of LEA proteins and structural characteristics suggest that they function in the protection of plant cells during dehydration or other stresses with a water-deficiency component. Additional evidence supports this hypothesis: firstly, functional in vitro protection assays have shown that several LEA proteins are able to protect diverse enzyme activities against different stresses (e.g. Rinne et al. 1999; Hara et al. 2001; Bravo et al. 2003) and secondly, transgenic and genetic approaches have also shown the relationship between the accumulation of some LEA proteins and enhanced stress protection (Imai et al. 1996; Xu et al. 1996; Ismail et al. 1999; Zhang et al. 2000; Hara et al. 2003).

LEA protein members of groups 2, 3, 4 and 5 from $C$. plantagineum have been characterised. They accumulate during dehydration and have been found in all cell types, accumulating abundantly in the cytoplasm or plastids (Michel et al. 1993, 1994; Schneider et al. 1993; Furini et al. 1996; Velasco et al. 1998; Ditzer et al. 2001). Promoters of four $C$. plantagineum LEA genes have been analysed in tobacco and Arabidopsis. All of them were highly active in seeds and pollen, two naturally dehydration-tolerant tissues (Michel et al. 1993, 1994; Furini et al. 1996; Velasco et al. 1998). Several cis-elements involved in ABA-induced gene expression have been identified in promoters of Leagenes from C. plantagineum (Bartels and Salamini 2001). One important group are the ABREs (ABA-responsive elements) which contain the G-box ACTG core motif, but they do not seem to be the sole determinants for $\mathrm{ABA}$ and dehydration response (Michel et al. 1993, 1994).

Here we report the characterisation of a novel early dehydration-inducible gene $C p E d i-9$ from $C$. plantagineum. $C p E d i-9$ is expressed in response to plant dehydration, salt stress and ABA treatment in vegetative tissues and constitutively in mature seeds. Sequence analysis of CpEdi-9 did not reveal significant homology with known genes, although it shares some predicted structural features with LEA proteins. In contrast to the C. plantagineum Lea genes studied, expression in leaves in response to dehydration is earlier and restricted to the phloem cells of the vascular bundles. Like other promoters of Lea genes and ABA-responsive genes, the $C p E d i-9$ promoter is active in stomatal guard cells, pollen and mature seeds, when analysed in transgenic plants. The $C p E d i-9$ promoter directs reporter gene expression in response to dehydration and ABA treatment and its activity is mainly localised in phloem cells of the vascular tissue. CpEdi-9 encodes a hydrophilic boiling-stable protein, which may extend the known classes of Lea genes. It could be involved in the protection of vascular tissues of C. plantagineum during early phases of dehydration.

\section{Materials and methods}

\section{Plant material}

Plants of Craterostigma plantagineum Hochst., originally collected in South Africa, were grown under controlled environmental conditions as described by Bartels et al. (1990). In dehydration experiments, mature plants were removed from their pots and water was withheld. The water content of untreated plants was set to $100 \%$ of relative water content and the water loss was monitored during the dehydration process (Smith-Espinoza et al. 2003). Plants were treated for salt stress in hydroponic cultures in Hoagland solution supplemented with the indicated $\mathrm{NaCl}$ concentrations. For ABA treatments, excised leaves were placed on water containing $100 \mu \mathrm{M}$ ABA $(+/-$ cis trans isomer; Sigma-Aldrich, München, Germany).

Plants of Nicotiana tabacum L. cv Samsun and Arabidopsis thaliana (L.) Heynh. (ecotype Columbia) were propagated and grown as described by Velasco et al. (1998). Seeds were obtained from the collection at the Max Planck Institute, Köln, Germany.

Six-week-old Arabidopsisplants were treated by submerging the aerial parts in an aqueous solution with or without $100 \mu \mathrm{M}$ ABA for $10 \mathrm{~s}$ twice a day for 2 days. In dehydration experiments water was withheld for 5 days from soil-grown Arabidopsis plants.

The ABA treatment in transgenic tobacco was applied to 8-day-old in vitro-grown seedlings by transferring them to medium without or with $100 \mu \mathrm{M}$ ABA for $24 \mathrm{~h}$. 
Nucleic acid analysis

Extraction of nucleic acids, RNA and DNA blot analyses were carried out as described in Bartels et al. (1990). The CpEdi-9 cDNA insert was labelled with ${ }^{32} \mathrm{P}$ by random prime labelling (Feinberg and Vogelstein 1984).

General molecular biology methods were performed according to standard procedures (Sambrook et al. 1989).

Isolation of the CpEdi-9 cDNA and genomic clone

The CpEdi- 9 cDNA clone was isolated by differentially screening a cDNA library constructed from mRNA isolated from 1-h-dehydrated $C$. plantagineum leaves (Bockel et al. 1998). The genomic library was constructed by cloning partially digested DNA fragments into the phage lambda vector EMBL4 (Michel et al. 1994). The library was screened using the CpEdi-9 cDNA clone as a probe.

\section{Production of recombinant EDI-9 protein}

The recombinant EDI-9 protein was produced and purified as polypeptide containing an N-terminal His-tag carried in the pQE30 vector following the instructions of the manufacturer (QIAexpress; Qiagen, Germany). Recombinant EDI-9 protein was affinitypurified on Ni-NTA Agarose resin (QIAexpress; Qiagen) under native conditions. Purified EDI-9 protein was precipitated with $2.5 \mathrm{vol}$. of acetone and resuspended in $150 \mathrm{mM}$ potassium phosphate buffer ( $\mathrm{pH} 7.5)$

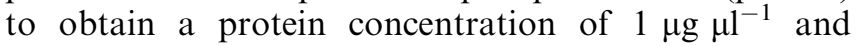
stored at $-20^{\circ} \mathrm{C}$ until used.

DNA sequencing and computer analysis

DNA was sequenced using a dideoxynucleotide sequencing kit with the T7 polymerase (Pharmacia LKB, Freiburg, Germany) and the Ready reaction Dideoxy Terminator Cycle Sequencing Kit Prism (Applied Biosystems, Darmstadt, Germany) with a model 373A DNA sequencer (Applied Biosystems). DNA and protein sequences were analysed using programs from the University of Wisconsin Genetics Computer Group (Devereux et al. 1984).

Primer extension analysis

A 17-mer oligonucleotide complementary to the strand position +73 to +89 was end-labelled with ${ }^{33} \mathrm{P}$ and hybridised to $10 \mu \mathrm{g}$ poly(A) ${ }^{+}$RNA isolated from 2 -hdehydrated $C$. plantagineum leaves. The hybridisation was carried out for $3 \mathrm{~h}$ at $42^{\circ} \mathrm{C}$ in $250 \mathrm{mM} \mathrm{KCl}$ and $10 \mathrm{mM}$ Tris- $\mathrm{HCl}$ (pH 7.9). First-strand cDNA synthesis was performed in $50 \mathrm{mM} \mathrm{NaCl}$ with 20 units of AMV reverse transcriptase (Life Sciences, St. Petersburg, USA) for $1 \mathrm{~h}$ at $42^{\circ} \mathrm{C}$. The extended product was analysed in a $6 \%$ polyacrylamide-urea gel using the $17-$ mer oligonucleotide for sequencing the genomic CpEdi-9 clone as reference.

Construction of the $C p E d i-9$ promoter $\beta$-glucuronidase $(G U S)$ gene, and plant transformation

A promoter fragment (1,293 bp in length) of the $C p E d i$ 9 gene was amplified by PCR and subcloned into the binary vector $\mathrm{pBI} 101.2$ containing the GUS gene coding sequence and the nopaline synthase (NOS) polyadenylation signal (Jefferson et al. 1987) creating the plasmid pBIpEdi9. The pBIpEdi9 plasmid was transferred to Agrobacterium tumefaciens (strain LBA4404) for plant transformation. Leaf discs of Nicotiana tabacum (cv. Samsun) were transformed as described by Horsch et al. (1985). After inoculation with Agrobacterium harbouring pBIpEdi-9, transformed cells were selected in a shoot-inducing medium supplemented with $50 \mathrm{mg} \mathrm{l}^{-1}$ kanamycin (Sigma) and $500 \mathrm{mg} \mathrm{l}^{-1}$ cefotaxime (Hoechst). Young shoots were transferred to a root-inducing medium containing $100 \mathrm{mg} \mathrm{l}^{-1}$ kanamycin and $500 \mathrm{mg} \mathrm{l}^{-1}$ cefotaxime. Rooted plantlets were transferred to soil and grown in the greenhouse.

Plants of Arabidopsis thaliana (L.) Heynh. (ecotype Columbia) were transformed using the vacuum method as described by Bechtold et al. (1993).

The insertion of the pBIpEdi-9 plasmid in transgenic plants was confirmed by PCR using an internal primer of the GUS gene and a primer located in the $C p E d i-9$ promoter.

\section{In-situ hybridisation of RNA}

Leaves from $C$. plantagineum plants dehydrated for $4 \mathrm{~h}$ were fixed in $4 \%$ formaldehyde, $0.1 \%(\mathrm{v} / \mathrm{v})$ glutaraldehyde in $0.1 \mathrm{M}$ sodium phosphate buffer $(\mathrm{pH}$ 7.2) for $16-24 \mathrm{~h}$ at $4^{\circ} \mathrm{C}$. The plant material was dehydrated in a graded ethanol-xylene series and embedded in Paraplast. Sections $(10 \mu \mathrm{m}$ thick) were prepared using a microtome (Leica RM 2065). The Edi-9 cDNA clone was subcloned in the vector pBluescript SK (Stratagene, Heidelberg, Germany) and used as template for synthesis of sense and antisense digoxigenin-labelled ribo probes following the manufacturer's instructions (Boehringer, Mannheim, Germany). Probes were hydrolysed to an average size of $150 \mathrm{bp}$ before hybridisation. Mounted slides were hybridised overnight at $50^{\circ} \mathrm{C}$. After hybridisation the sections were incubated with $40 \mu \mathrm{g} \mathrm{ml}^{-1}$ RNase A and then washed several times with $2 \times \operatorname{SSPE}(1 \times \operatorname{SSPE}=0.18 \mathrm{M} \mathrm{NaCl}, 10 \mathrm{mM}$ $\mathrm{NaH}_{2} \mathrm{PO}_{4}, 2 \mathrm{mM}$ EDTA) at $45^{\circ} \mathrm{C}$. Digoxigenin-labelled RNA probes were detected using anti-digoxigenin alkaline-phosphatase conjugate (Boehringer). Slides 
were incubated with 5-bromo-4-chloro-3-indolyl-phosphate/nitroblue tetrazolium (BCIP/NBT), rinsed with water and counterstained with Safranin O.

\section{Detection of GUS activity}

Transformed tobacco and Arabidopsis plants were examined at different developmental stages and upon dehydration or ABA treatment for GUS activity. For quantitative GUS assays, protein extracts from transgenic plants were mixed with the substrate solution [10 mM 4-methylumbelliferyl-D-glucuronide (MUG), $50 \mathrm{mM} \mathrm{NaH}{ }_{2} \mathrm{PO}_{4}, 10 \mathrm{mM}$ EDTA, $10 \mathrm{mM} \beta$-mercaptoethanol, $0.1 \%$ Triton $\mathrm{X}-100, \mathrm{pH} 7.0$ ] and assayed as described by Jefferson et al. (1987). The GUS activity was quantified with a fluorometer (LS30; Perkin Elmer, Rodgau, Germany). Total protein concentrations were determined using the BioRad (Munich, Germany) protein assay kit. GUS activity is expressed as pmol 4methylumbelliferone (MU) $\mathrm{mg}^{-1} \mathrm{~min}^{-1}$.

For histochemical GUS staining the samples were immersed in GUS staining solution $[1 \mathrm{mM} \mathrm{X-}$ Gluc (5-bromo-4-chloro-3-indolyl- $\beta$-D-glucuronide) in $100 \mathrm{mM}$ sodium phosphate buffer $(\mathrm{pH}$ 7.0) containing $10 \mathrm{mM}$ EDTA, $0.5 \mathrm{mM}$ potassium ferrocyanide, $0.5 \mathrm{mM}$ potassium ferricyanide and $0.01 \%$ Triton $\mathrm{X}-100]$, vacuum-infiltrated and incubated overnight at $37^{\circ} \mathrm{C}$. Plant pigments were extracted with three changes of $95 \%(\mathrm{v} / \mathrm{v})$ ethanol. Tissue for microscopic sections (12 $\mu \mathrm{m}$ thick) was dehydrated in a graded ethanolxylene series, embedded in Paraplast and sectioned using a microtome (Leica RM 2065). Paraplast was removed from sections by treatments with xylene. Hand-cut sections were prepared from fixed, stained tissue using a razor blade. Tobacco and Arabidopsis epidermal peels were removed from the abaxial surface of the leaves.

\section{Results}

Isolation and sequence analysis of the $C p E d i-9$ gene from Craterostigma plantagineum

In a search for genes expressed early in response to dehydration, the CpEdi-9 (= Craterostigmaplantagineum early dehydration-induced) gene was identified (Bockel et al. 1998). The CpEdi-9 cDNA clone isolated from the library was $375 \mathrm{bp}$ long containing the 3 'poly(A)-tail but truncated at the $5^{\prime}$-end. Screening of a genomic library (Michel et al. 1994) resulted in the isolation of a genomic clone with a 2.9-kb EcoRI fragment containing the $C p E d i-9$ gene. The genomic clone was identical to the cDNA and contained an intron of $96 \mathrm{bp}$ with the conserved GT/AT splicing site (Fig. 1a). The 5'-end of the CpEdi-9 transcript was determined to be 41 nucleotides upstream of the ATG (Fig. 1b). The deduced amino acid sequence indicates the presence of a termination codon 410 nucleotides downstream of the transcription start-site. The deduced CpEDI-9 protein is 91 amino acids long with a predicted size of $10.1 \mathrm{kDa}$. The CpEDI-9 protein is very hydrophilic, soluble after boiling (Fig. 2), and the carboxy terminus of the protein is predicted to form an amphiphilic $\alpha$-helix (Fig. 1a). The composition of the CpEDI-9 protein is biased towards Lys (12.1\%) and Glu (16.5\%), and lacks Cys, Phe and Trp. Genomic DNA blot analysis suggests that $C p E d i-9$ is present as a single-copy gene in the $C$. plantagineum genome (data not shown). When the CpEDI-9 sequence was compared with nucleotide and protein sequences available in public databases, no significant homology was found. However, when database searches were carried out without filter settings, some hits were obtained. Among proteins with the closest similarities are LEA proteins, and alignments are shown in Fig. 3. CpEDI-9 displays some features of LEA proteins from plants, like the maize group-3 LEA protein or the dehydrin-like BDN1 protein from the resurrection plant Boea crassifolia, and a group-3 LEA-like protein AavLEA1 from the nematode Aphelenchus avenae. The conservation of Lys and Asp/Glu residues is the most remarkable feature (Fig. 3), and sequence identity between EDI-9 and the aligned LEA-like proteins ranged between 32 and $22 \%$ identity. No continuous stretches of sequence homologies were identified and therefore CpEDI-9 defines a new class of small hydrophilic proteins.

The CpEdi-9 transcript is expressed in response to dehydration, salt stress or ABA treatment and accumulates in mature seeds

We analysed the effect of dehydration and salt stress on the expression of the CpEdi-9 gene in C. plantagineum leaves and roots (Fig. 4). No expression was detected in vegetative tissues of untreated plants, but the transcript accumulated rapidly in dehydrated leaves and roots. Highest expression levels were reached during the first hours of dehydration, and then the expression in leaves declined to relatively low levels, whereas in roots the transcript level was maintained during further dehydration. The CpEdi-9 transcript accumulated faster in response to dehydration than previously isolated Lea genes from C. plantagineum, e.g. the dehydrin CDeT6-19 transcript (Fig. 4; Schneider et al. 1993). The CpEdi-9 gene was also induced by application of exogenous ABA or salt treatment (Fig. 4). The CpEdi-9 gene is constitutively expressed in mature seeds, a naturally dehydrated tissue. The transcript level was lower in seeds than in 4-h-dehydrated leaves but similar to that found in seeds for the Lea-type dehydrin CDeT6-19 (Fig. 4).

The spatial distribution of the CpEdi-9 transcript was investigated by in situ hybridisation using the RNA transcript of CpEdi-9 as a probe on sections of 4-hdehydrated leaves of $C$. plantagineum. This analysis showed that the CpEdi-9 transcript was mainly localised 
Fig. 1 a Nucleotide sequence of the Craterostigma plantagineum CpEdi-9 gene and the deduced protein sequence. Exons are printed in upper-case letters and introns or untranslated sequences are shown in lowercase letters. Amino acid residues corresponding to a putative $\alpha$-helix are marked with a double line. The nucleotides and amino acids are numbered on the left-hand side. The transcription start and the putative TATA box are indicated in reverse print. Putative regulatory cis-elements are in italics and underlined. The sequence has been submitted to GenBank database and has been given the accession number AY382595. b Determination of the transcription start site of the $C p E d i-9$ gene by primerextension analysis. A 17-mer oligonucleotide was hybridised to poly $\left(\mathrm{A}^{+}\right)$RNA isolated from 2-h-dehydrated

C. plantagineum leaves. The oligonucleotide was used for the reference sequence. $A, C, G$, and $T$ Dideoxynucleotides; $E x$, extension product a

-1293 tcaaacgtcg tataaaggag cggatccggt aaagaaggta cqtcttcaaa

-1243 ccttaagagc cgagtttgag gcattgcata tgaagcatga tgaggttgtg -1193 tcggactact tctcaagggt attagcaata actaatcaac tttttataga -1143 catcagaaat aggcaaaact ctatcgctaa tctaataatc acagatctaa -1093 taactcatgt gaactgatta tcgaagtcga catattaaca ggtagtttcq -1043 aactgataat cacatgaaaa agatgagttt cgaatcgaac ctccttcgtc -993 cagttgttag ctgcctgcat tcaacagatg actgcgattt gggggaatga -943 gatagggtat taaagtaatt tcagcattac tactctggge tggattaata -893 atcgatccta cccacatctg attacttatc atgcctggec caaattatta -843 acgagggcct ggcttttctc atgggcttca gaccaataac tcttaaatgo -793 aactgaacag ataaagctgg ttaagtggac atttgtcatg gataatccca -743 caaagtaaac gggcccttaa caacttaagt acttattaca aaactatacg -693 atcttatacc atctccgatc aataccaata atcagatgca aacatacaaa -643 aatactccaa ccgacactca aacgcatgcc cgaatggat tttatgtcat -593 ttctctgccg ttttcatttg acatcaacac ataaatttt atctctcacc -543 atgctaaatt tagtaattaa gttttattac aaattactg taattagctt -493 attatcattt aattacttt actaatatac cacatgtata atgttcaagt -443 tagaadaad atatttatad tccacgaaat atcatttatt tatattatgt -393 gqgtaaagtt ggaaagtttc taatataatg agacgcattg aaaactataa -343 attgatgcga tgcaaattgt gaatgagttt aatgagcgga gaaagaataa -293 tcccattttg aatttgggga tgagtttgca tggaagaacg agtttttcgg -243 ttgagatgtt tcctcccatt tatcaaatt ttattgtgct gatcataagg -193 accattttta acaatttaat aacataage atctccacgt tatggcagtt $-143$ aaccalcaag aatct $\overline{c c c a c}$ caagtccatc gactccatat tctccacgta actcaaacg tctataaata gcataaaga actcaacaat gtçacagat tgcagggaaa aaacacacag agaactcgtt tcctATGCAA CACCATCAGC $\begin{array}{llllllllll}M & Q & H & H & Q & L\end{array}$

TACAGAGACA GAACTCCATG GATACTTCCA AGgtaagaag atcgctaact $\begin{array}{lllllllllllllllllllll}Q & R & Q & N & S & M & D & T & S & K\end{array}$

accgtaactc aaacatgcgc atatgtgctt aacgtccatt cgaatttctt actctttgt cggaatctgt aatgtcagCG TGATGAGAAT ATAACCGACG $\begin{array}{llllllllllllll}R & D & E & N & I & T & D & E\end{array}$

AAGGTGCGGT GGAGAAGAAG GTGGAGACGG TGAACTATCG ACACGGGCCG

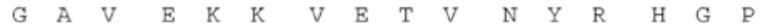
GGCTCGGAGA AGGAGCCCGC CGAAGAGAAG GTTGAGGTGA CTCATCTGCC $\begin{array}{lllllllllllllllllllllllll}G & S & E & K & E & P & A & E & E & K & V & E & V & T & H & L & P\end{array}$ CCACACCGAC GAAGAGAAGC CAGGCGTTTT AAAGGAAGCT GCTGAGAAAG $\begin{array}{ccccccccccccccccc}\text { H } & \text { T } & \text { D } & \text { E } & \text { E } & \text { K } & \text { P } & \text { G } & \text { V } & \text { L } & \text { K } & \text { E } & \text { A } & \text { A } & \text { E } & \text { K } & \text { V } \\ \text { TTGCGGAGAA } & \text { GATAGAGTCT } & \text { GCTAAGGCAG } & \text { CTGCTAAGCC } & \text { CAGTGGTCAA }\end{array}$ $\begin{array}{llllllllllllllll}A & E & K & I & E & S & A & K & A & A & A & K & P & S & G & Q\end{array}$ AATTGAaaag aatttatgta aacgctacat tctggtttgt gatctgaat $\mathrm{N}$ *

ctatccaacc tgggattttc actggttttg caactaatga atcgtatcaa b

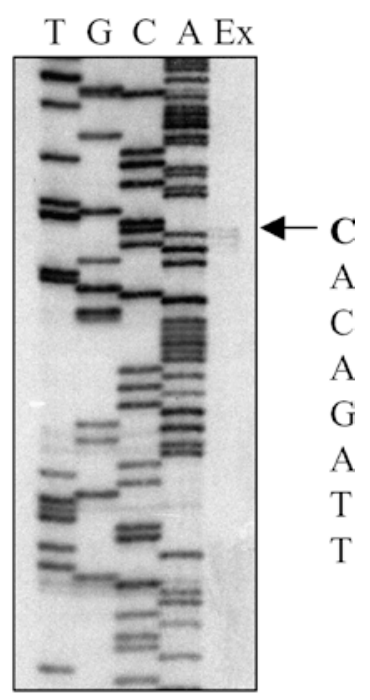

in the phloem cells of the vascular bundles (Fig. 5). In summary, the $C p E d i-9$ gene represents a novel gene, rapidly induced during dehydration and mainly restricted to the phloem and mature seeds of C. plantagineum.

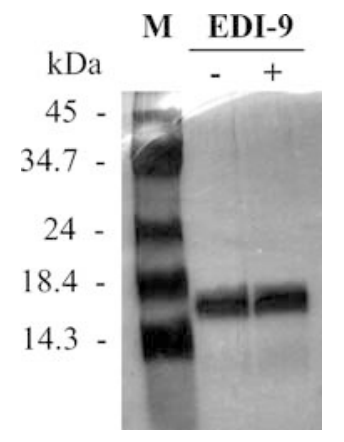

Fig. 2 The recombinant $C$. plantagineum EDI-9 protein is soluble after boiling. An aliquot of the EDI-9 protein $\left(1 \mu \mathrm{g} \mu \mathrm{l}^{-1}\right.$ in $150 \mathrm{mM}$ potassium phosphate buffer $\mathrm{pH} 7.5$ ), was heated at $95^{\circ} \mathrm{C}$ for $10 \mathrm{~min}$, then cooled to room temperature and centrifuged at $12,000 \mathrm{~g}$ for $15 \mathrm{~min}$ at $4^{\circ} \mathrm{C}$. Four $\mu \mathrm{l}$ of the heated supernatant $(+$ lane $)$ and of the untreated purified protein (- lane) were separated in a $16 \%$ SDS-PAGE gel and stained with Coomassie brilliant blue R250 (Merck)
Search for potential regulatory sequences in the $C p E d i-9$ promoter

The PlantCARE database (Lescot et al. 2002) was searched to identify several potential regulatory

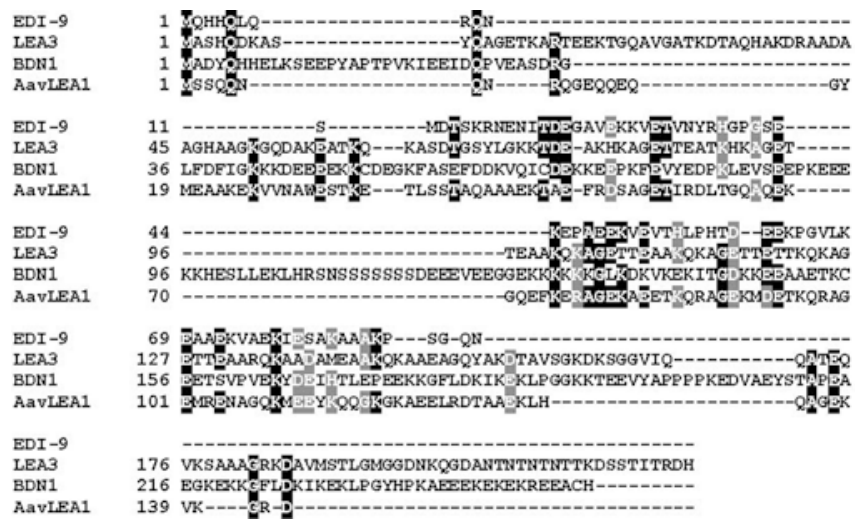

Fig. 3 Alignment of the amino acid sequences of $C$. plantagineum EDI-9 (CpEDI-9; AY382595), the maize protein LEA3 (Q42376), the dehydrin-like BDN1 protein from the resurrection plant B. crassifolia(AAF01465) and the group-3 LEA-like protein AavLEA1 from the nematode A. avenae (Q95V77). Amino acids that are identical or conservative substitutions in at least three of the sequences are boxed in black or grey, respectively 


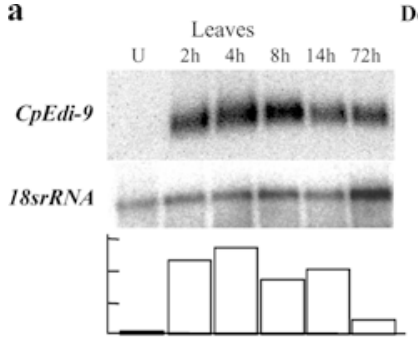

b
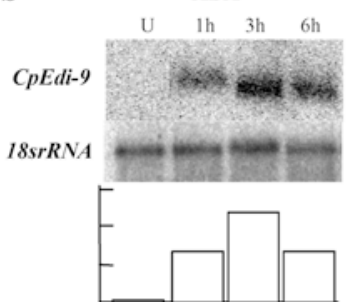

Dehydration

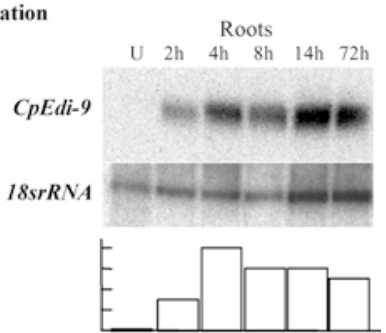

c
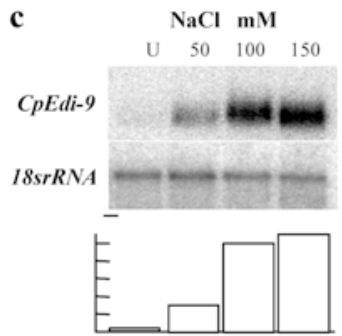

d

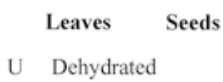

$4 \mathrm{~h} 48 \mathrm{~h}$

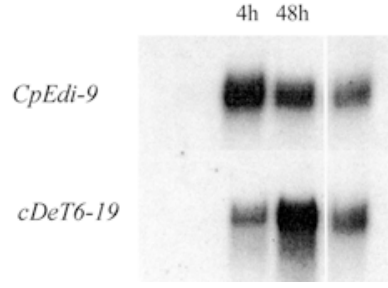

Fig. 4 a-c RNA blot analysis showing the expression of the C. plantagineum CpEdi-9 transcript in response to a dehydration, $\mathbf{b}$ ABA $(100 \mu \mathrm{M})$ and csalt treatment $(\mathrm{NaCl}$ for $6 \mathrm{~h})$. Membranes carrying $2 \mu \mathrm{g}$ of poly(A) ${ }^{+}$RNA were probed with the CpEdi-9 cDNA insert. All filters were hybridised with a ribosomal probe to monitor loading of RNA. The relative intensity of the hybridising bands was calculated using the 18srRNA signal as a reference. The graph below each autograph gives the relative signal intensity. In the dehydration kinetics the relative water content (RWC) was set to $100 \%$ in untreated plants (lane $U$ ) and the corresponding RWC values for dehydrated plants were $62 \%, 39 \%, 25 \%, 18 \%$ and $15 \%$ for $2,4,8,14$ and $72 \mathrm{~h}$ of dehydration. d The CpEdi-9 transcript accumulates in mature seeds. Total RNA ( $30 \mu \mathrm{g}$ in each lane) from untreated $(U)$ and dehydrated $(4 \mathrm{~h}$ and $48 \mathrm{~h})$ leaves and mature seeds of $C$. plantagineum was hybridised with the CpEdi-9 cDNA insert to compare relative expression levels. The blot was also hybridised with the dehydrin CDeT6-19 cDNA insert to compare expression levels (Bartels et al. 1990)

sequences in the $C p E d i-9$ promoter. Motifs known to play a role in transcriptional control were found: a TATA box at -31 and several ABA- and stressresponsive elements (Table 1). At least six motifs with the core sequence ACGT, known as the G-box of the ABREs, were found, and a sequence with a high degree of homology to a 'coupling element' (CE1), which is active in combination with ABREs but not alone, was also identified. Further, one Myb and two Myb-like recognition sites, and one sequence which closely resembles an ABA-inducible Sph-containing element or Sph box (ASCE), which is conserved in many seedspecific promoters (Hattori et al. 1992), were identified (Table 1). Two regions rich in $\mathrm{A} / \mathrm{T}$ are located between -539 and $-424 \mathrm{bp}$, and they may act as general enh-

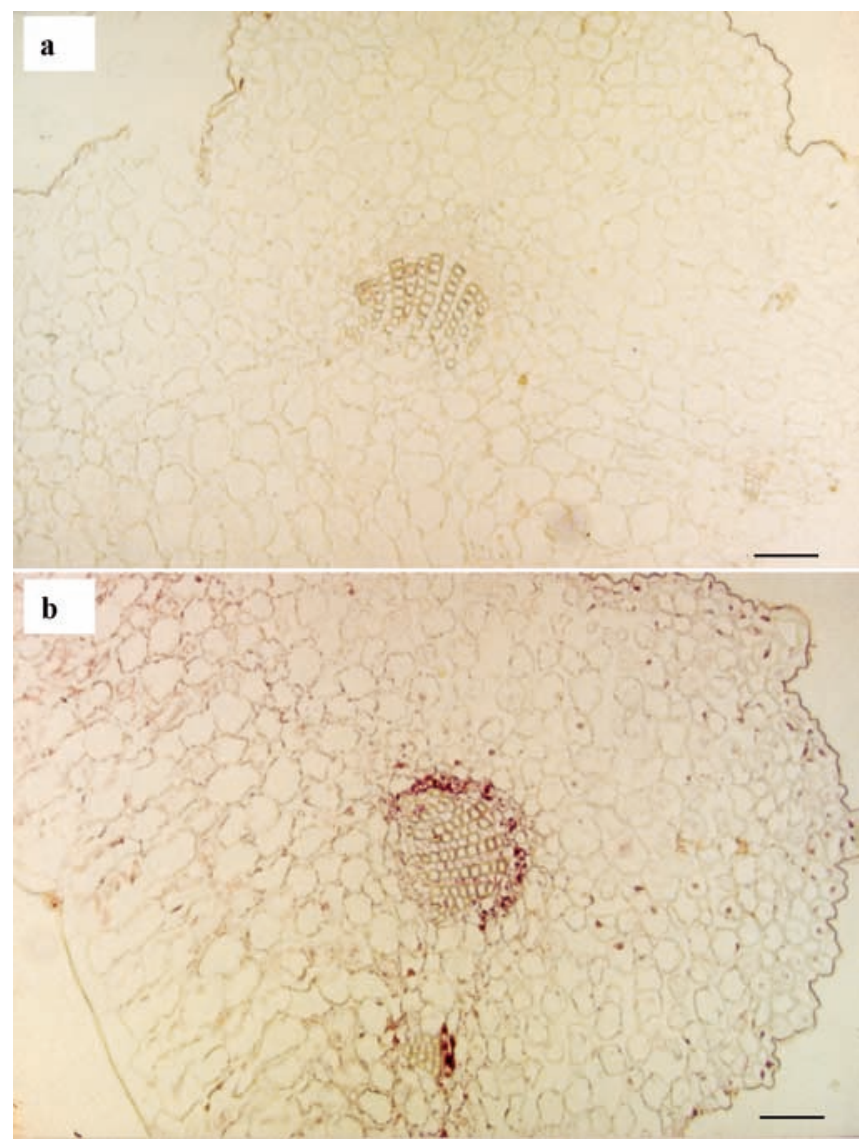

Fig. 5a,b In situ hybridisation of CpEdi-9 to sections of 4-hdehydrated $C$. plantagineum leaves. Bright-field micrographs are shown of tissue sections hybridised with a digoxigenin-labelled CpEdi-9 riboprobe. a Leaf section hybridised with a sense probe. $\mathbf{b}$ Leaf section hybridised with an antisense probe. Bars $=200 \mu \mathrm{m}$

ancers of gene expression (Bustos et al. 1989). We also identified the sequence of the PB core motif, which is present in promoters of pollen-specific genes of tomato (Twell et al. 1991). A sequence comparison of the CpEdi$95^{\prime}$ regulatory sequence with other phloem-specific promoters revealed the presence of motifs related to phloem-specific expression. First, CCA sequence repeats were identified, which have been suggested to contribute to phloem specificity (Hehn and Rhode 1998). The second element related to phloem expression in the CpEdi-9 promoter is a 13-bp motif, which is located close to the TATA box, as in other phloem-specific promoters (Yoshida et al. 2002). The third element is a GATA motif found in the rice tungro bacilliform virus and known to be important for phloem-specific gene expression (Yin et al. 1997). Sequences matching the consensus sequence of the GATA motif, $\mathrm{A}(\mathrm{N})_{3}$ GATA, were found at $-1044,-947$ and -789 bp in the CpEdi9 promoter (Table 1). The same motif was found also in the promoters of plant genes expressed in the phloem: glutamine synthase from pea (Brears et al. 1991), a plasma membrane $\mathrm{H}^{+}$-ATPase from Arabidopsis (DeWitt et al. 1991) and a potato invertase (Hedley et al. 2000). 
Table 1 Putative regulatory elements in the promoter of the Craterostigma plantagineum CpEdi-9gene

\begin{tabular}{|c|c|c|}
\hline Motif & Position & $\begin{array}{l}\text { Sequence } \\
\text { in } C p E d i-9\end{array}$ \\
\hline ABRE core ACGT $^{\mathrm{a}}$ & $\begin{array}{l}-1254 \\
-1064 \\
-157 \\
-127 \\
-48 \\
-26\end{array}$ & 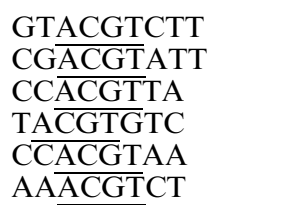 \\
\hline CE1-like element ${ }^{\mathrm{b}}$ & -79 & TGCCACCAA \\
\hline $\begin{array}{c}\text { Myb recognition } \\
\text { site PyAACTG }\end{array}$ & -794 & CAACTGAA \\
\hline $\begin{array}{l}\text { Myb-like } \\
\text { recognition site }\end{array}$ & -1083 and -1044 & GAACTGAT \\
\hline ASCE-like ${ }^{c}$ & -864 & CATGCCTG \\
\hline $\mathrm{A} / \mathrm{T}$ rich regions & $\begin{array}{l}-539 \text { to }-465 \\
-443 \text { to }-424\end{array}$ & $\begin{array}{l}86 \% \mathrm{~A} / \mathrm{T} \\
95 \% \mathrm{~A} / \mathrm{T}\end{array}$ \\
\hline PB-core like ${ }^{\mathrm{d}}$ & -396 & TGTGGGT \\
\hline $\begin{array}{l}\text { CCA repeated } \\
\text { sequence }\end{array}$ & -96 to -50 & 7 times $\mathrm{CCA}$ \\
\hline $\begin{array}{l}\text { Phloem-specific } \\
\text { element (13 bp) }\end{array}$ & -199 & ATAAGGACCATTT \\
\hline $\mathrm{A}(\mathrm{N})_{3}$ GATA motif & $\begin{array}{l}-1044 \\
-947 \\
-789\end{array}$ & $\begin{array}{l}\text { AACTGATA } \\
\overline{\text { ATGAGATA }} \\
\overline{\text { AACA }}\end{array}$ \\
\hline
\end{tabular}

${ }^{a}$ The ACGT motif is the core sequence of ABRE G-box elements (Busk and Pages 1998)

${ }^{b} \mathrm{CE} 1$ : Coupling Element 1 acts in combination with a G-box-type ABRE. The sequence of the CE1 element is TGCCACCGG (Busk and Pages 1998)

${ }^{\mathrm{c}}$ The ASCE (ABA-inducible Sph-Containing Element) motif is CATGCATG (Hattori et al. 1992)

${ }^{\mathrm{d}}$ The sequence of the PB core motif identified in the promoters of pollen-specific genes of tomato is TGTGGTT (Twell et al. 1991)

Analysis of the $C p E d i-9$ promoter in transgenic plants

In order to confirm regulatory elements which determine the specific expression pattern of $C p E d i-9,1,293 \mathrm{bp}$ of the promoter region including $41 \mathrm{bp}$ of the leader sequence of the $C p E d i-9$ gene were fused to the $G U S$ gene (for details, see Materials and methods). GUS expression was analysed by in situ tissue staining and in quantitative fluorometric assays. The results shown here were obtained from two representative tobacco lines (4.4 and 4.8) and three Arabidopsis lines (4.2, 4.4 and 4.5). In tobacco, $\mathrm{T}_{0}$ and $\mathrm{T}_{1}$ plants were analysed, and in Arabidopsis, $\mathrm{T}_{1}$ and $\mathrm{T}_{2}$.

Mature tobacco seeds showed high GUS activity, which was reduced by a factor of 3-6 after 1 day of seed imbibition in water (Fig. 6). During plantlet development, GUS activity progressively decreased in transgenic tobacco seedlings. In 8-day-old seedlings, GUS activity was 100 - to 50 -times lower than in mature seeds. Histochemical localisation showed staining mainly in embryos of mature seeds and low GUS expression in the surrounding endosperm tissue (Fig. 7a). After 1 day of germination, GUS activity was located at the emerging radicle. In 3-day-old seedlings, GUS expression was restricted to the main vein of the cotyledons and the transition zone between stem and root (Fig. 7b). In mature tobacco plants, low GUS activity was

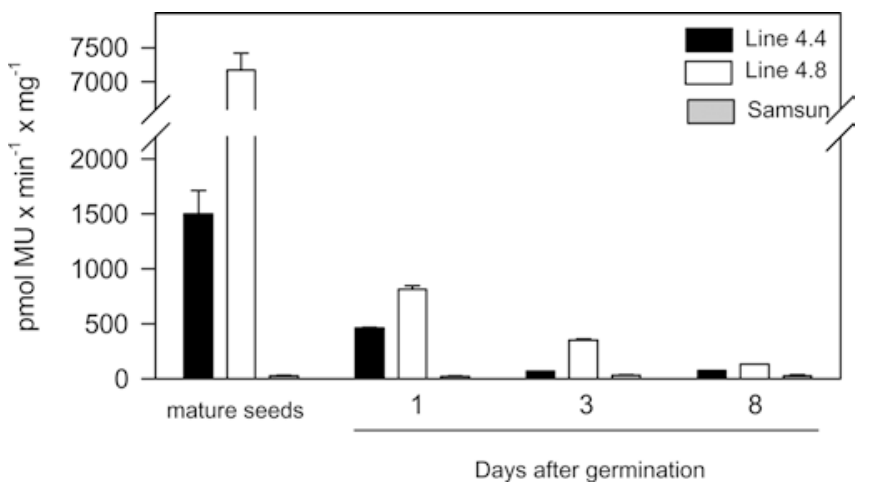

Fig. 6 Time-course of promoter GUS activity during seed germination of tobacco (Nicotiana tabacum) transformed with the CpEdi-9 promoter GUS construct. Seeds from two independent transformed lines (lines 4.4 and 4.8) and untransformed wild-type plants (Samsun) were analysed. Data are the mean of three independent measurements. The SE is indicated

found in leaves, ranging between 20 and $50 \mathrm{pmol}$ MU $\mathrm{min}^{-1} \mathrm{mg}^{-1}$ protein in the different transgenic lines. Histochemical analysis of GUS expression in leaves showed a strong signal in stomatal guard cells (Fig. 7c) and trichomes (Fig. 7d), and a weak staining in some of the leaf veins (data not shown). In the leaf pedicel and stem the GUS activity was restricted to the phloem, mainly to the internal phloem, and to some guard cells and trichomes (Fig. 7e-g). High GUS expression also occurred in desiccated pollen grains (data not shown). ABA treatment increased GUS activity in 8-day-old tobacco seedlings (Fig. 8) and histochemical analysis showed that expression was localised to the vascular system of the cotyledons and the root (Fig. 7h,i). Induction of GUS activity was also detected by dehydration stress in detached leaves from mature plants (Fig. 8).

Similar results to those with tobacco were obtained from transgenic Arabidopsis plants. The highest GUS activity in 6-week-old Arabidopsisplants was found in mature pollen grains (Fig. 7j), followed by the roots and stems (Fig. 7k); a very weak activity was detected in leaves (Fig. $7 \mathrm{~m}$ ). Histochemical staining of roots, stems and leaves revealed that GUS expression was restricted to the vascular system, and only to the main vein in leaves. Detailed analysis of GUS expression in Arabidopsis stems showed that the activity was localised to the phloem of vascular bundles (Fig. 71). When 6-week-old Arabidopsis plants were treated with ABA an increase in GUS activity was observed mainly associated with the vascular system, but when plants were subjected to dehydration stress the GUS signal was more intense and was also present in the minor-vein system, more specifically in the free vein endings in the centre of the areoles (Fig. 7n,o).

\section{Discussion}

Many genes are differentially expressed during dehydration of the desiccation-tolerant plant $C$. plantagineum 
Fig. 7a-o Histochemical localisation of GUS expression directed by the $C p E d i-9$ promoter in tobacco $(\mathbf{a}-\mathbf{i})$ and Arabidopsis $(\mathbf{j}-\mathbf{o})$ plants transformed with the $C p E d i$ 9promoter GUS construct. a Mature tobacco seeds $(\times 10)$. b One-day-old (right) and 3-dayold (left) germinating tobacco seedlings $(\times 8)$. c GUS activity in guard cells in an epidermal peel of a tobacco leaf $(\times 150)$. d Trichomes of a tobacco leaf $(\times 150)$. e Tobacco petiole section $(\times 12)$. f,g Tobacco stem section $(\mathbf{f} ; \times 5)$ and

magnification of the vascular tissue $(\mathbf{g} ; \times 400)$. h,i Eight-dayold tobacco seedling untreated (h) and treated (i) with ABA $(100 \mu \mathrm{M})$ for $24 \mathrm{~h}(\times 2)$. $\mathbf{j}$ Mature Arabidopsis flowers $(\times 4)$. k, I Stem section of a 6-week-old Arabidopsis plant that had not been watered for 5 days $(\mathbf{k} ; \times 10)$ and magnification of the a vascular bundle (l; $\times 400)$. $\mathbf{m}-\mathbf{0}$ Arabidopsis rosette leaves from a 6 -week-old untreated plant (m), a plant not watered for 5 days (n) and a plant treated with ABA $(100 \mu \mathrm{M})$ for 2 days $(\mathbf{0} ; \times 3)$. $c$ Cortex, ip internal phloem, $p$ pith parenchyma, $p h$ phloem, op outer phloem, $x$ xylem
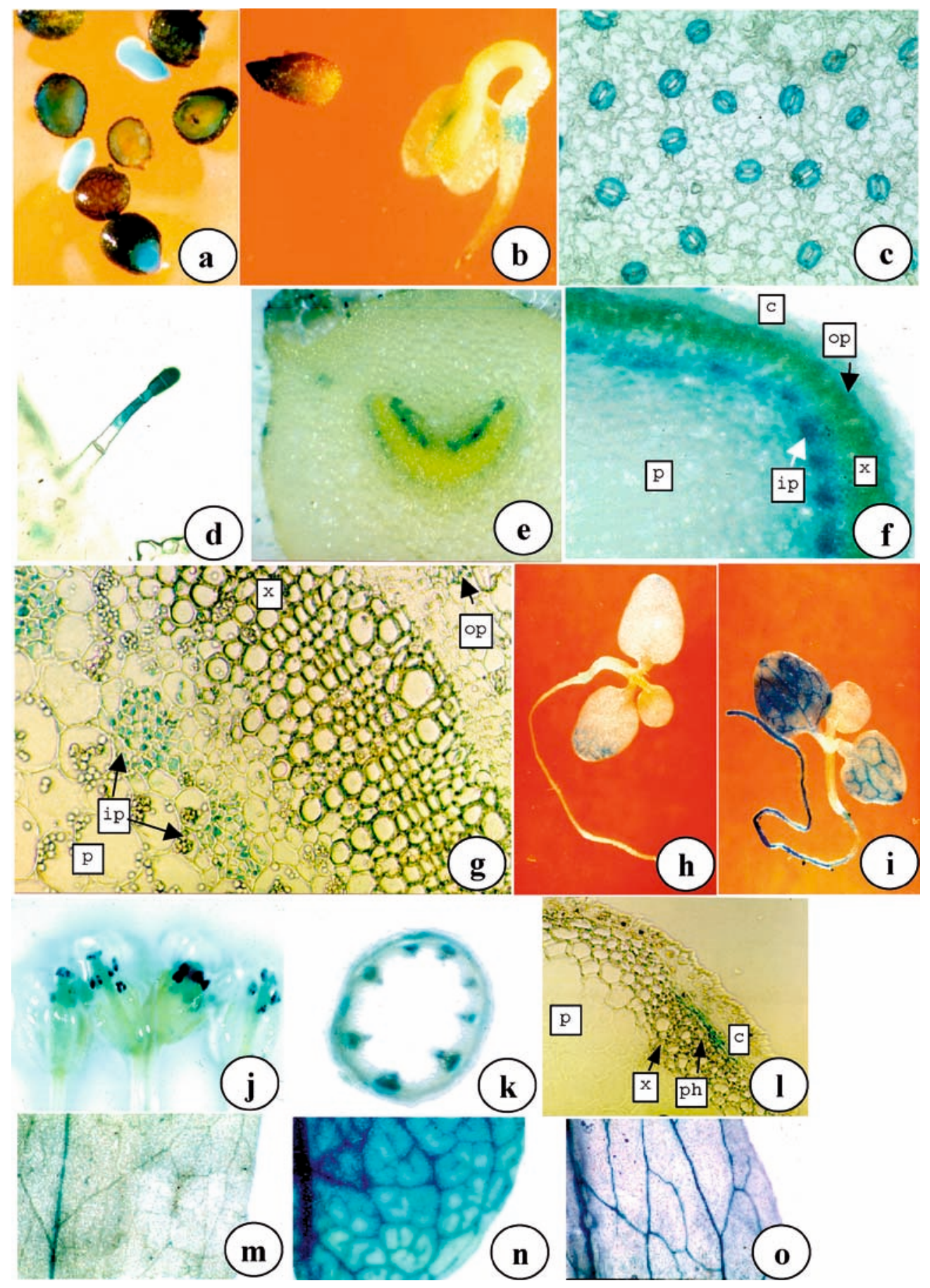

The expression behaviour of $C p E d i-9$ is different from previously described dehydration-induced genes. It was surprising that no significant sequence similarities were detected, either on the nucleotide or on the protein level, to genes present in public databases. However, when criteria such as structural and physicochemical characteristics of the predicted protein are analysed, resemblance is found to LEA proteins. The $C p E d i-9$ gene encodes a protein which does not coagulate after boiling and which has a high content of hydrophilic amino acids, lacking aromatic amino acids and Cys. These characteristics are the main features of group-2 LEA to be of importance. In work presented here we describe $C p E d i-9$, a novel, early dehydration-responsive gene.

(Bartels et al. 1990; Bockel et al. 1998) and they appear to be important in preventing the deleterious effects of (reviewed in Bartels and Salamini 2001). A relevant role in cellular protection has been attributed to LEA proteins (Schneider et al. 1993; Velasco et al. 1998; Ditzer et al. 2001), to detoxifying enzymes, e.g. aldehyde dehydrogenase (Kirch et al. 2001; Sunkar et al. 2003), and to some heat-shock proteins (Alamillo et al. 1995). Besides proteins, the accumulation of sucrose also seems 


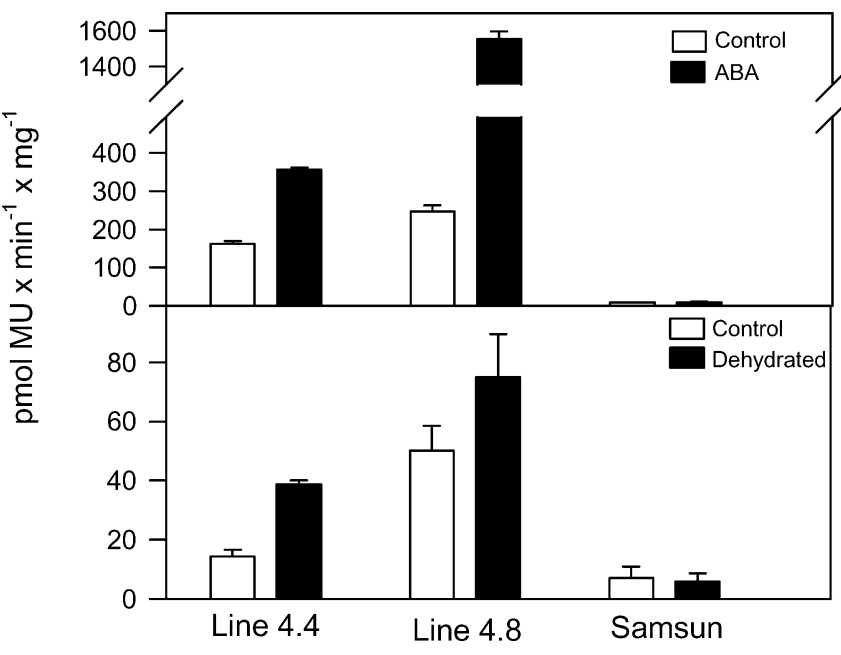

Fig. 8 The $C p E d i-9$ promoter is responsive to dehydration and ABA in transgenic tobacco. GUS activity in 8-day-old seedlings treated for $24 \mathrm{~h}$ with $100 \mu \mathrm{M}$ ABA (upper graph) or in detached leaves dehydrated for $4 \mathrm{~h}$ (lower graph). Dehydration treatment was given to the youngest fully developed leaf of each plant above the 5th internode. The Samsun line represents untransformed tobacco plants and seedlings. Data are shown as the mean of at least three independent measurements and error bars indicate the SE

proteins (dehydrins; Close 1997; Cuming 1999). Moreover, amino acid sequence analysis predicts that the protein exists mainly as random-coil structure except for the presence of an amphipathic $\alpha$-helix at the C-terminus, also a structural characteristic of dehydrins and group-3 LEAs (Dure et al. 1989; Ingram and Bartels 1996; Close 1997; Cuming 1999). The predicted amphipathic $\alpha$-helix in dehydrins, termed the $\mathrm{K}$ segment, is highly conserved and present in one to several copies. This structure may be of functional importance and has been suggested to allow interactions with other hydrophobic or hydrophilic cellular surfaces, stabilizing them during dehydration (Close 1997; Cuming 1999). Recent structural analysis of the Aav LEA1 nematode protein showed that it exists in an unfolded structure, but an increased formation of $\alpha$-helices and possibly coiled-coil formation are observed under dehydration conditions (Goyal et al. 2003). Similar observations were reported for the dehydrin-like CDeT 6-19 protein from C. plantagineum (Lisse et al. 1996); EDI-9 may likewise exist as an unfolded molecule in hydrated conditions. The fact that CpEDI-9 shares features with group-2 and group-3 LEA proteins but does not fall into either group (Fig. 3) supports the suggestion that $C p E d i-9$ represents a novel Lea-like gene which so far is unique to $C$. plantagineum. This gene may have been evolved under the pressure of extreme dehydration tolerance, which requires abundant expression of protective hydrophilic proteins.

The expression pattern of $C p E d i-9$ is similar to that of other known dehydration-induced genes and very consistent with a protective function for CpEDI-9. The CpEdi-9 transcript accumulates in mature seeds of C. plantagineum (Fig. 4d), and transgenic plants show that the high promoter activity in the desiccated embryo decreases rapidly during germination (Fig. 6), which again points to a role during dehydration. Expression of the $C p E d i-9$ gene is induced by dehydration, salt treatment and exogenous application of ABA (Fig. 4). In contrast to all previously described dehydration-induced genes, including Leagenes from C. plantagineum (Piatkowski et al. 1990; Schneider et al. 1993; Ditzer et al. 2001), CpEdi-9 is expressed in leaves early during dehydration and it is spatially restricted to the phloem (Fig. 5). To investigate whether the phloem-specific expression is retained in the promoter of the $C p E d i-9$ gene, promoter GUS activities were analysed in transgenic plants. This analysis was performed in heterologous systems like Arabidopsis and tobacco in order to test whether the CpEdi-9 promoter has biotechnological potential and is suitable to drive the expression of desired target genes in a stress- and tissue-specific manner. The analysis of transgenic plants supported the in situ hybridisation results and suggests that the function of CpEDI-9 might be restricted to vascular tissues. Accumulation of CpEDI-9 could provide the vascular tissue of the resurrection plant with an early defence against desiccation.

The fact that the expression of $C p E d i-9$ is restricted to phloem cells of the vascular bundles during dehydration of $C$. plantagineum(Fig. 5) makes it an excellent candidate to analyse promoter elements responsible for this specific expression pattern. This work has identified in the $5^{\prime}$ regulatory region of the $C p E d i-9$ gene a number of cis-acting elements required for ABA-inducibility in many stress-responsive genes (Table 1; Busk and Pages 1998; Leung and Giraudat 1998; Rock 2000). However, the functionality of these motifs in the $C p E d i-9$ promoter remains to be demonstrated since modified core ABREs present in other Lea gene promoters from C. plantagineum are not always a major determinant of ABA or drought responsiveness (Michel et al. 1993, 1994). The $C p E d i-9$ promoter drives expression of the reporter gene to phloem cells (Fig. 7e-g,k,l). Interestingly, in leaves from dehydrated transgenic Arabidopsis plants, in contrast to ABA-treated plants, GUS expression was not just restricted to the main vein system but was also found in minor veins (Fig. 7n), which are sites of intensive phloem loading. Several promoters from plants (Brears et al. 1991; DeWitt et al. 1991; Hedley et al. 2000; Yoshida et al. 2002),Agrobacterium (Guevara-Garcia et al. 1993) and viruses (BhattacharyyaPakrasi et al. 1993; Hehn and Rohde 1998) have been reported to drive expression of the reporter gene in the phloem of transgenic plants. The CpEdi-9 promoter contains three types of element related to phloem cellspecific expression (Table 1). The contribution of these motifs to phloem-specific expression in other genes has been demonstrated by loss-of-function analysis (Yin et al. 1997; Hehn and Rohde 1998). The phloem-specific 13-bp element and the GATA motifs are conserved between virus and plant promoters, implying an important role for these motifs for gene expression in the phloem. Lea gene promoters from C. plantagineum and other higher plants have been reported to be highly active in 
the naturally desiccation-tolerant tissues pollen and seeds (specifically embryos; Cuming 1999; Bartels 1999), which supports a role for these proteins in desiccation. Previous studies of seed-specific genes have shown that A/T-rich sequences in the promoter can act as general enhancers of seed specific expression (Bustos et al. 1989). Such sequences are present in the $C p E d i-9$ promoter and could promote expression in seeds. Concerning the CpEdi-9promoter activity in pollen, a sequence was identified resembling the $\mathrm{PB}$ core motif that is present in the pollen-specific LAT genes of tomato (Twell et al. 1991) and in the Lea AtEml gene from Arabidopsis (Hull et al. 1996); it may function as transcriptional enhancer in pollen.

In conclusion, we propose that $C p E d i-9$ defines a new class of genes. The predicted protein shares some physiological and biochemical properties with $L E A$ proteins. The localisation in the phloem tissue is consistent with the hypothesis that $C p E d i-9$ might contribute to a specialised protecting function of the vascular bundles during the desiccation process.

Acknowledgments We thank F. Salamini for advice during the work and critically reading the manuscript, B. Eilts for technical assistance, S. Berger for help with preparing the manuscript and C.J. Smith-Espinoza for performing the C. plantagineum salt treatments. M.-J.R. was supported by a postdoctoral fellowship from the Spanish Ministry of Science and Technology and a research contract from the EU Biotech Programme (BIO-CT98-5006).

\section{References}

Alamillo J, Almoguera C, Bartels D, Jordano J (1995) Constitutive expression of small heat shock proteins in vegetative tissues of the resurrection plant Craterostigma plantagineum. Plant Mol Biol 29:1093-1099

Bartels D (1999) Late embryogenesis abundant (LEA) proteins: expression and regulation in the resurrection plant Craterostigma plantagineum, Chapter 19. In: MF Smallwood MF, Clavert CM, Bowles DJ (eds) Plant responses to environmental stress. BIOS, Oxford, pp 143-160

Bartels D, Salamini F (2001) Desiccation tolerance in the resurrection plant Craterostigma plantagineum. A contribution to the study of drought tolerance at the molecular level. Plant Physiol 127:1346-1353

Bartels D, Schneider K, Terstappen G, Piatkowski D, Salamini F (1990) Molecular cloning of abscisic acid modulated genes which are induced during desiccation of the resurrection plant Craterostigma plantagineum. Planta 181:27-34

Bartels D, Furini A, Ingram J, Salamini F (1996) Responses of plants to dehydration stress: a molecular analysis. Plant Growth Regul 20:111-118

Bechtold N, Ellis J, Pelletier G (1993) In planta Agrobacterium mediated gene transfer by infiltration of adult Arabidopsis thaliana plants. CR Acad Sci Paris Life Sci 316:1194-1196.

Bhattacharyya-Pakrasi M, Peng J, Elmer JS, Laco G, Shen P, Kaniewska MB, Kononowicz H, Wen F, Hodges TK, Beachy RN (1993) Specificity of a promoter from the rice tungro bacilliform virus for expression in phloem tissues. Plant $\mathbf{J}$ 4:71-79

Bockel C, Salamini F, Bartels D (1998) Isolation and characterization of genes expressed during early events of the dehydration process in the resurrection plant Craterostigma plantagineum. J Plant Physiol 152:158-166
Bravo LA, Gallardo J, Navarrete A, Olave N, Martinez J, Alberdi M, Close TJ. Corcuera LJ (2003) Cryoprotective activity of a cold-induced dehydrin purified from barley. Physiol Plant 118:262-269

Brears T, Walker EL, Coruzzi GM (1991) A promoter sequence involved in cell-specific expression of the pea glutamine synthetase $G S 3 A$ gene in organs of transgenic tobacco and alfalfa. Plant J 1:235-244

Busk PK, Pages M (1998) Regulation of abscisic acid-induced transcription. Plant Mol Biol 37:425-435

Bustos MB, Guiltinan J, Jordano J, Begum D, Kalkan FA, Hall TC (1989) Regulation of beta-glucuronidase expression in transgenic tobacco plants by an $\mathrm{A} / \mathrm{T}$ rich,cis-acting sequence found upstream of a french bean beta-phaseolin gene. Plant Cell 1:839-853

Close TJ (1997) Dehydrins: a commonalty in the response of plants to dehydration at low temperature. Physiol Plant 100:291-296

Colmenero-Flores JM, Campos F, Garciarrubio A, Covarrubias AA (1997) Characterization of Phaseolus vulgaris cDNA clones responsive to water deficit-identification of a novel late embryogenesis abundant-like protein. Plant Mol Biol $35: 393-405$

Cuming A (1999) LEA proteins. In: Shewry P, Casey R (eds) Seed proteins. Kluwer, Dordrecht, pp 753-780

Devereux J, Haerberli P, Smithies O (1984) A comprehensive set of sequence analysis programs for the VAX. Nucleic Acids Res $12: 387-395$

DeWitt ND, Harper JF, Sussman MR (1991) Evidence for a plasma membrane proton pump in phloem cells of higher plants. Plant J 1:121-128

Ditzer A, Kirch HH, Nair A, Bartels D (2001) Molecular characterization of two alanine-rich Lea genes abundantly expressed in the resurrection plant C. plantagineum in response to osmotic stress and ABA. J Plant Physiol 158:623-633

Dure III L (1993) Structural motifs in Lea proteins. In: Plant responses to cellular dehydration during environmental stress. Close T, Bray EA (eds) Current topics in plant physiology, vol 10. The American Society of Plant Physiologists, Rockville, MD, pp 91-103

Dure III L, Crouch M, Harada J, Ho T-H, Mundy J, Quatrano R, Thomas T, Sung ZR (1989) Common amino acid sequence domains among the Lea proteins of higher plants. Plant Mol Biol 12:475-486

Feinberg AP, Vogelstein B (1984) A technique for radiolabelling DNA restrcition endonuclease fragments to high specific activity. Anal Biochem 137:266-267

Furini A, Parcy F, Salamini F, Bartels D (1996) Differential regulation of two aba-inducibie genes from Craterostigma plantagineum in transgenic Arabidopsis plants. Plant Mol Biol 30:343-349

Gaff DF (1971) Desiccation-tolerant plants in southern Africa Science 174:209-224

Galau GA, Hughes DW, Dure III L (1986) Abscisic acid induction of clones cotton late embryogenesis abundant (Lea) mRNA. Plant Mol Biol 7:155-170

Goyal K, Tisi L, Basran A, Browne J, Burnell A, Zurdo J, Tunnacliffe A (2003) Transition from natively unfolded to folded state induced by desiccation in an anhydrobiotic nematode protein. J Biol Chem 278:12977-12984

Guevara-Garcia A, Mosqueda-Cano G, Argüello-Astorga G, Simpson J, Herrera-Estrella L (1993) Tissue-specific and wound-inducible pattern of expression of the mannopine synthase promoter is determined by the interaction between positive and negative cis-regulatory elements. Plant J 4:495-505

Hara M, Terashima S, Kuboi T (2001) Characterization and cryoprotective activity of cold-responsive dehydrin from Citrus unshiu. J Plant Physiol 158:1333-1339

Hara M, Terashima S, Fukaya T, Kuboi T (2003) Enhancement of cold tolerance and inhibition of lipid peroxidation by citrus dehydrin in transgenic tobacco. Planta 217:290-298 
Hattori T, Vasil V, Rosenkrans L, Hannah LC, McCarty DR, Vasil IK (1992) The Viviparous-1gene and abscisic acid activate the $\mathrm{C} 1$ regulatory gene or anthocyanin biosynthesis during seed maturation in maize. Genes Devel 6:609-618

Hedley PE, Maddison AL, Davidson D, Machray GC (2000) Differential expression of invertase genes in internal and external phloem tissues of potato (Solanum tuberosumL.) J Exp Bot 51:817-821

Hehn A, Rohde W (1998) Characterization of cis-acting elements affecting strength and phloem specificity of the coconut foliar decay virus promoter. J Gen Virol 79:1495-1499

Horsch RB, Frey J, Hoffmann N, Eichholtz D, Rogers S, Fraley R (1985) A simple method for transferring genes into plants. Science 227:1229-1231

Hull GA, Bies N, Twell D, Delseny M (1996) Analysis of a promoter of an abscisic acid responsive late embryogenesis abundant gene of Arabidopsis thaliana. Plant Sci 114:181-192

Imai R, Chang L, Ohta A, Bray EA, Takagi M (1996) A lea-class gene of tomato confers salt and freezing tolerance when expressed in Saccharomyces cerevisae. Gene 170:243-248

Ingram J, Bartels D (1996) The molecular basis of dehydration tolerance in plants. Annu Rev Plant Physiol Plant Mol Biol 47:377-403

Ismail AM, Hall AE, Close TJ (1999) Allelic variation of a dehydrin gene cosegregates with chilling tolerance during seedling emergence. Proc Natl Acad Sci USA 96:13566-13570

Jefferson RA, Kavanagh TA, Bevan MW (1987) GUS fusion: betaglucuronidase as a sensitive and versatile gene fusion marker in higher plants. EMBO J 6:3901-3907

Kirch HH, Nair A, Bartels D (2001) Novel ABA- and dehydrationinducible aldehyde dehydrogenase genes isolated from the resurrection plants Craterostigma plantagineum and Arabidopsis thaliana. Plant J 28:555-567

Leopold AC, Bruni F, Williams RJ (1992) Water in dry organisms. In: Somero GN, Osmond CB, Bolos CL (eds) Water and life. Springer, Berlin Heidelberg New York, pp 161-169

Leung J, Giraudat J (1998) Abscisic acid signal transduction. Annu Rev Plant Physiol Plant Mol Biol 49:199-222

Lescot M, Dehais P, Thijs G, Marchal K, Moreau Y, Van de Peer Y, Rouze P, Rombauts S (2002) PlantCARE, a database of plant $c i s$-acting regulatory elements and a portal to tools for in silico analysis of promoter sequences. Nucleic Acids Res. 30:325-327

Lisse T, Bartels D, Kalbitzer HR, Jaenicke R (1996) The recombinant dehydrin-like desiccation stress protein from the resurrection plant Craterostigma plantagineum displays no defined three-dimensional structure in its native state. Biol Chem 377:555-561

Michel D, Salamini F, Bartels D, Dale P, Baga M, Szalay A (1993) Analysis of a desiccation and ABA-responsive promoter isolated from de resurrection plant Craterostigma plantagineum. Plant J 4:29-40

Michel D, Furini A, Salamini F, Bartels D (1994) Structure and regulation of an ABA- and desiccation-responsive gene from the resurrection plant Craterostigma plantagineum. Plant Mol Biol 24:549-560
Phillips JR, Hilbricht T, Salamini F, Bartels D (2002) A novel abscisic acid- and dehydration-responsive gene family from the resurrection plant Craterostigma plantagineum encodes a plastid-targeted protein with DNA-binding activity. Planta 215:258-266

Piatkowski D, Schneider K, Salamini F, Bartels D (1990) Characterization of five abscisic acid-responsive cDNA clones isolated from the desiccation-tolerant plant Craterostigma plantagineum and their relationship to other water-stress genes. Plant Physiol 94:1682-1688

Rinne PLH, Kaikuranta PLM, van der Plas LHW, van der Schoot C (1999) Dehydrins in cold-acclimated apices of birch (Betula pubescens Ehrh.): production, localization and potential role in rescuing enzyme function during dehydration. Planta 209:377388

Rock CD (2000) Pathways to abscisic acid-regulated gene expression. New Phytol 148:357-396

Sambrook J, Fritsch EF, Maniatis T (1989) Molecular cloning: a laboratory manual, 2nd edn. Cold Spring Harbor Laboratory Press, Cold Spring Harbor, NY

Schneider K, Wells B, Schmelzer E, Salamini F, Bartels D (1993) Desiccation leads to the rapid accumulation of both cytosolic and chloroplastic proteins in the resurrection plant Craterostigma plantagineum Hochst. Planta 189:120-131

Smith-Espinoza CJ, Richter A, Salamini F, Bartels D (2003) Dissecting the response to dehydration and salt $(\mathrm{NaCl})$ in the resurrection plant Craterostigma plantagineum. Plant Cell Environ 26:1307-1315

Sunkar R, Bartels D, Kirch HH (2003) Overexpression of a stressinducible aldehyde dehydrogenase gene from Arabidopsis thaliana in transgenic plants improves stress tolerance. Plant $\mathrm{J}$ 35:452-464

Twell D, Yamaguchi J, Wing RA, Ushiba J, McCormick S (1991) Promoter analysis of genes that are coordinately expressed during pollen development reveals pollen-specific enhancer sequences and shred regulatory elements. Genes Dev 5:496-507

Velasco R, Salamini F, Bartels D (1998) Gene structure and expression analysis of the drought-and abscisic acid-responsive cdet11-24 gene family from the resurrection plant Craterostigma plantagineum Hochst. Planta 204:459-471

Xu D, Duan X, Wang B, Hong B, Ho T-HD, Wu R (1996) Expression of a late embryogenesis abundant protein gene, HVA1, from barley confers tolerance to water deficit and salt stress in transgenic rice. Plant Physiol 110:249-257

Yin Y, Zhu Q, Dai S, lamb C, Beachy R (1997) RF2a, a bzip transcriptional activator of the phloem-specific rice tungro bacilliform virus promoter, functions in vascular development. EMBO J 16:5247-5259

Yoshida K, Mohri T, Nishiguchi M, Tazaki K (2002) Robinia pseudoacacia inner-bark lactin promoter expresses GUS also predominantly in phloem of transgenic tobacco. J Plant Physiol 159:757-764

Zhang L, Ohta A, Takagi M, Imai R (2000) Expression of plant group 2 and group 3 leagenes in Saccharomyces cerevisiae revealed functional divergence among LEA proteins. J Biochem 127:611-616 